\title{
Nonlegume Parasponia andersonii Deploys a Broad Rhizobium Host Range Strategy Resulting in Largely Variable Symbiotic Effectiveness
}

\author{
Rik H. M. Op den Camp, ${ }^{1}$ Elisa Polone,,${ }^{1,2}$ Elena Fedorova, ${ }^{1}$ Wim Roelofsen, ${ }^{3}$ Andrea Squartini, ${ }^{2}$ \\ Huub J. M. Op den Camp, ${ }^{4}$ Ton Bisseling, ${ }^{1,5}$ and René Geurts ${ }^{1}$ \\ ${ }^{1}$ Department of Plant Sciences, Laboratory of Molecular Biology, Wageningen University, Droevendaalsesteeg 1, 6708 PB, \\ Wageningen, The Netherlands; '2Department of Agricultural Biotechnologies, Universitá di Padova, Viale dell'Universitá 16, \\ 35020 Legnaro (Padova), Italy; ${ }^{3}$ Department of Plant Sciences, Laboratory of Microbiology, Dreijenplein 10, Building \\ Number 316, 6703 HB Wageningen, The Netherlands; ${ }^{4}$ Department of Microbiology, IWWR, Radboud University Nijmegen, \\ Heyendaalseweg 135, 6525 AJ, Nijmegen, The Netherlands; ${ }^{5}$ College of Science, King Saud University, Post Office Box 2455 , \\ Riyadh 11451, Saudi Arabia
}

Submitted 30 November 2011. Accepted 21 March 2012.

The non-legume genus Parasponia has evolved the rhizobium symbiosis independent from legumes and has done so only recently. We aim to study the promiscuity of such newly evolved symbiotic engagement and determine the symbiotic effectiveness of infecting rhizobium species. It was found that Parasponia andersonii can be nodulated by a broad range of rhizobia belonging to four different genera, and therefore, we conclude that this non-legume is highly promiscuous for rhizobial engagement. A possible drawback of this high promiscuity is that low-efficient strains can infect nodules as well. The strains identified displayed a range in nitrogen-fixation effectiveness, including a very inefficient rhizobium species, Rhizobium tropici WUR1. Because this species is able to make effective nodules on two different legume species, it suggests that the ineffectiveness of $P$. andersonii nodules is the result of the incompatibility between both partners. In $P$. andersonii nodules, rhizobia of this strain become embedded in a dense matrix but remain vital. This suggests that sanctions or genetic control against underperforming microsymbionts may not be effective in Parasponia spp. Therefore, we argue that the Parasponia-rhizobium symbiosis is a delicate balance between mutual benefits and parasitic colonization.

Most legume species can engage a symbiosis with nitrogenfixing soil bacteria collectively referred to as rhizobia. In addition to the common occurrence within the legume family (Fabaceae), this nitrogen-fixing rhizobium symbiosis has evolved only once in another plant species (Trinick 1973). This independent evolutionary event occurred in a small genus of tropical trees found in the family Cannabaceae called Parasponia. The Parasponia-rhizobium symbiosis is considered to have arisen

Nucleotide sequence data is available in the GenBank database under accession numbers JQ889855, JQ889856, JQ889857, JQ889858, JQ889859，JQ889860，JQ889861，JQ889862，JQ889863，JQ889864, JQ889865, JQ889866.

Corresponding author: R. Geurts; Telephone: +31317484712; E-mail: rene.geurts@wur.nl

* The $\boldsymbol{e}$-Xtra logo stands for "electronic extra" and indicates that seven supplementary figures are published online and that Figures 1, 2, and 3 appear in color online. only recently when compared with legumes (Op den Camp et al. 2011). We investigated two aspects of the Parasponia-rhizobium symbiosis; namely, its promiscuity and the effectiveness of the nodules formed.

Symbiotic rhizobium bacteria form a diverse group of more than 10 genera within the phylum of the Proteobacteria that have gained the capacity to live in symbiosis with legumes. Many legume species display a restricted host range and can only be nodulated by a limited number of bacterial species or even strains. On the other hand, highly promiscuous legumes are also known. Legumes that display a restricted host range or are highly promiscuous do not form unified taxonomic groups; especially promiscuous species are dispersed within the family Fabaceae (Perret et al. 2000). Specificity for rhizobium microsymbionts generally is thought to have emerged upon co-evolution between host and microbe (Martinez-Romero 2009; Masson-Boivin et al. 2009; Provorov and Vorobyov 2008). This implies that high promiscuity for nitrogen-fixing rhizobia was the ground state of ancestral host plants (Sprent 1994). We aimed to test this hypothesis by studying the promiscuity of the more recently evolved non-legume rhizobium host, the genus Parasponia.

The evolutionarily recent origin of the Parasponia genus is best supported by its very close phylogenetic relation with the genus Trema (Sytsma et al. 2002). Furthermore, the symbiotic engagement with rhizobia displays several basal characteristics suggesting a recent emergence. A characteristic of the genus Parasponia being a relatively young host for rhizobia is the infection mechanism by which the endosymbiont enters the plant. In Parasponia spp., rhizobia enter by means of so-called crack entry, which is considered to be a basal mode of infection and only found in a very limited number of legume species (Charpentier and Oldroyd 2010; Goormachtig et al. 2004; Madsen et al. 2010; Sprent 2007). In contrast, in most legumes, rhizobia enter by the stringent host-controlled mechanism of epidermal root hair entry (Charpentier and Oldroyd 2010). In this entry mode, a single rhizobium attaches to a root hair and forms a microcolony, which is subsequently enclosed by the curling root hair. From the enclosed colony, an infection thread is formed, by which the rhizobia can progress into the root cortex. At the same time, a nodule primordium is initiated in the cortex, which will be reached by an infection thread that subsequently releases the rhizobia intracellularly to become 
nitrogen-fixing symbiosomes (Charpentier and Oldroyd 2010; Kouchi et al. 2010). Crack entry starts with colonization of the root surface, which coincides with cortical cell divisions that subsequently lead to rupturing of the epidermis. Rhizobia can also enter through cracks in the epidermis; for example, at the base of a lateral root (Charpentier and Oldroyd 2010; Webster et al. 1995). Next, rhizobia colonize intercellular spaces before forming infection threads, which will infect the nodule cortical cells (Capoen et al. 2010). Both epidermal root hair entry as well as crack entry are dependent on a genetic network triggered by a signal molecule excreted by rhizobium species, the Nod factor (Ardourel et al. 1994; Charpentier and Oldroyd 2010; Goormachtig et al. 2004; Op den Camp et al. 2011; Smit et al. 2007).

Among other factors, recognition of the bacterial Nod factor signaling molecules determines the host range of rhizobia. Nod factors are lipochitooligosaccharides consisting of three to five $\mathrm{N}$-acetyl-glucosamines and a lipid moiety. Rhizobium species-specific additions can be present on the terminal glucosamines, thereby determining host specific recognition (D'Haeze and Holsters 2002). Examples of such modifications are glycosylation, sulfation, acetylation, and methylation, for which the particular rhizobium species harbor specific nodulation (nod, nol, and noe) genes (Mergaert et al. 1997). The standing hypothesis is that that recognition of Nod factors by legume host plants is a driving force in co-evolution of both symbiotic partners and will result in host specificity (Arrighi et al. 2006; Downie 2010; Heath and Tiffin 2007; Limpens et al. 2003; Masson-Boivin et al. 2009; Radutoiu et al. 2003; Radutoiu et al. 2007). Former experiments showed that Parasponia spp. could be nodulated by a variety of rhizobium species (Becking 1983, 1992; Trinick and Galbraith 1980). However, at that time, the Nod factor structure was not yet resolved and rhizobium phylogeny was still based on cross-inoculation groups. Because the genus Parasponia has evolved the rhizobium symbiosis only recently, we hypothesize that, at least for the Nod factor recognition, less host specificity has evolved compared with legumes. To test this, we identified a diverse range of rhizobium species that nodulate Parasponia andersonii.

Here, we show that $P$. andersonii can form nodules with four rhizobium strains from four different genera. Based on the genome sequences of these four strains, we determined the core set of Nod factor biosynthesis genes essential to nodulate $P$. andersonii. We conclude that $P$. andersonii is highly promiscuous but whether a host and its microsymbiont have a successful interaction resulting in effective nitrogen fixation goes beyond Nod factor recognition (Downie 2010; Masson-Boivin et al. 2009). We found that the nitrogen-fixation rate varied greatly among the four strains tested. The least efficient nitrogen-fixing rhizobium strain also resulted in an aberrant nodule structure; host cells died, while the rhizobia persisted in these dead cells. This suggests that the Parasponia-rhizobium symbiosis is a delicate balance between mutual benefits and parasitic colonization.

\section{RESULTS}

\section{Genus Parasponia is highly promiscuous for rhizobial endosymbionts.}

Previous studies have shown that Parasponia spp. can be nodulated by Sinorhizobium sp. strain NGR234, though with a low nodulation efficiency (Op den Camp et al. 2011; Trinick 1980b; Trinick and Galbraith 1980; Webster et al. 1995). We aimed to find a more efficient rhizobium for future genetic studies on Parasponia spp. In the past, various rhizobium strains have been isolated from $P$. andersonii nodules during field expeditions in Papua New Guinea (Trinick 1980a). The two most efficient nodulating strains, CP279 and CP283, belong to the Bradyrhizobium genus (Trinick 1980a; Trinick and Hadobas 1988; Webster et al. 1995). We obtained stocks of these two strains but, unfortunately, these could not be revived. Instead, two other rhizobium species that represent distinct genera were tested for nodulation of $P$. andersonii plantlets; Bradyrhizobium elkanii WUR3 isolated from Chamaecrista fasiculata nodules and Rhizobium sullae IS123T isolated from Hedysarum coronarium (Squartini et al. 2002). Both species were found to nodulate $P$. andersonii plants highly efficiently ( $n=10 / 10)$. This $100 \%$ nodulation efficiency is much higher when compared with Sinorhizobium sp. strain NGR234, which nodulates only approximately $40 \%$ of the inoculated plants (Op den Camp et al. 2011; Webster et al. 1995).

Interestingly, $P$. andersonii plantlets grown for propagation under greenhouse conditions in commercial soil of mixed European origin were also frequently nodulated. From these nodules, several rhizobium isolates could be cultured that were genotyped using 16S rRNA gene sequencing. With these sequences, a 16S rRNA phylogenetic tree was constructed (Fig. 1). Based on this study, we identified two additional species as Wageningen University Rhizobium (WUR) strains: $R$. tropici strain WUR1 and Mesorhizobium plurifarium WUR2. Taken together, these results show that $P$. andersonii can be nodulated by a diverse range of rhizobium species and, therefore, we conclude that this species is highly promiscuous for rhizobial endosymbionts. Four strains from the genera Rhizobium, Mesorhizobium, Sinorhizobium, and Bradyrhizobium were selected for further studies; namely, R. tropici WUR1, M. plurifarium WUR2, Sinorhizobium sp. strain NGR234, and B. elkanii WUR3, respectively.

\section{Nod factor biosynthesis genes}

\section{of Parasponia-compatible rhizobia are highly diverse.}

The rhizobia that can nodulate $P$. andersonii make up a broad spectrum within the rhizobial phylogeny. In the case of legumes, the prokaryotic host range is frequently determined by the structure of the rhizobium-secreted Nod factors (MassonBoivin et al. 2009). We questioned to what extent the spectrum of Nod factor biosynthesis genes of the $P$. andersonii-compatible bacterial species is similar. Therefore, we sequenced the genomes of $R$. tropici WUR1, $M$. plurifarium WUR2, and $B$. elkanii WUR3 and compared nod, nol, and noe genes involved in Nod factor biosynthesis with the Sinorhizobium sp. strain NGR234 orthologs. Sinorhizobium sp. strain NGR234 is known to produce a large mixture of decorated Nod factors and, therefore, we anticipated that a large diversity of nod, nol, and noe genes involved in Nod factor biosynthesis would be present in this species (Perret et al. 2000; Schmeisser et al. 2009). In total, we investigated 17 genes, 12 of which are present in Sinorhizobium sp. strain NGR234 plus 5 additional genes; namely, nodE, nodF, nodH, nodL, and nodX, which are found in other species (e.g., R. leguminosarum bv. viciae 3841 or $S$. meliloti 1021) (Table 1). To identify putative orthologous nodulation genes in the sequenced genomes, FGENESB annotation in combination with BLAST and homology searches and manual curation were performed (Table 1). The sequence as well as organization of the nod gene region of $R$. tropici WUR 1 were shown to be highly homologous to the previously characterized nod gene regions of the $R$. tropici strains CIAT899 and CFN299 (Supplementary Fig. S1; Table 1) (Debellé et al. 1996; Folch-Mallol et al. 1996; Laeremans et al. 1996; Waelkens et al. 1995). Nod factor structures have been characterized for the CIAT899 strain and it was found that the composition of the Nod factor mixture is rather complex and highly variable in response to different environmental cues 
(Estévez et al. 2009; Folch-Mallol et al. 1996; Morón et al. 2005). To annotate nod genes in B. elkanii WUR3 and $M$. plurifarium WUR2, we compared nodulation gene sequences with those of the references strains $B$. japonicum USDA110 and M. loti MAFF303099, as well as with other well-annotated sequenced loci of related species (e.g., B. elkanii USDA94) (Supplementary Figs. S2 and S3; Table 1) (Kaneko et al. 2000, 2002; Yasuta et al. 2001). Comparing nodulation genes of $R$. tropici WUR1, M. plurifarium WUR2, B. elkanii WUR3, and Sinorhizobium sp. strain NGR234 revealed that these species have eight nodulation genes in common. These include nodA, $\operatorname{nod} B, \operatorname{nod} C, \operatorname{nod} L, \operatorname{nod} P, \operatorname{nod} Q, \operatorname{nod} S$, and $\operatorname{nod} U$. The $\operatorname{nod} P$ and $\operatorname{nod} Q$ genes encode two subunits of a sulfate adenylyltransferase that can donate a sulfate group to a sulfate trans- ferase. NodH (present in of $R$. tropici WUR1 and M. plurifarium WUR2) and noeE (present in B. elkanii WUR3 and Sinorhizobium sp. strain NGR234) encode such sulfotransferase, though both proteins have different specificities (Perret et al. 2000; Schwedock and Long 1990; Schwedock et al. 1994). NodL is known to O-acetylate the C6 carbon of the nonreducing glucosamine residue of the Nod factor backbone (Bloemberg et al. 1994). However, in the case of Sinorhizobium sp. strain NGR234, acetylated Nod factors have not been found, despite the occurrence of an nodL-like gene (Price et al. 1992). Highly homologous NodL-like proteins are also found in nonsymbiotic bacteria belonging to the family Rhizobiaceae (Supplementary Fig. S4), underlining that these proteins fulfill nonsymbiotic functions. Because phylogeny or homology

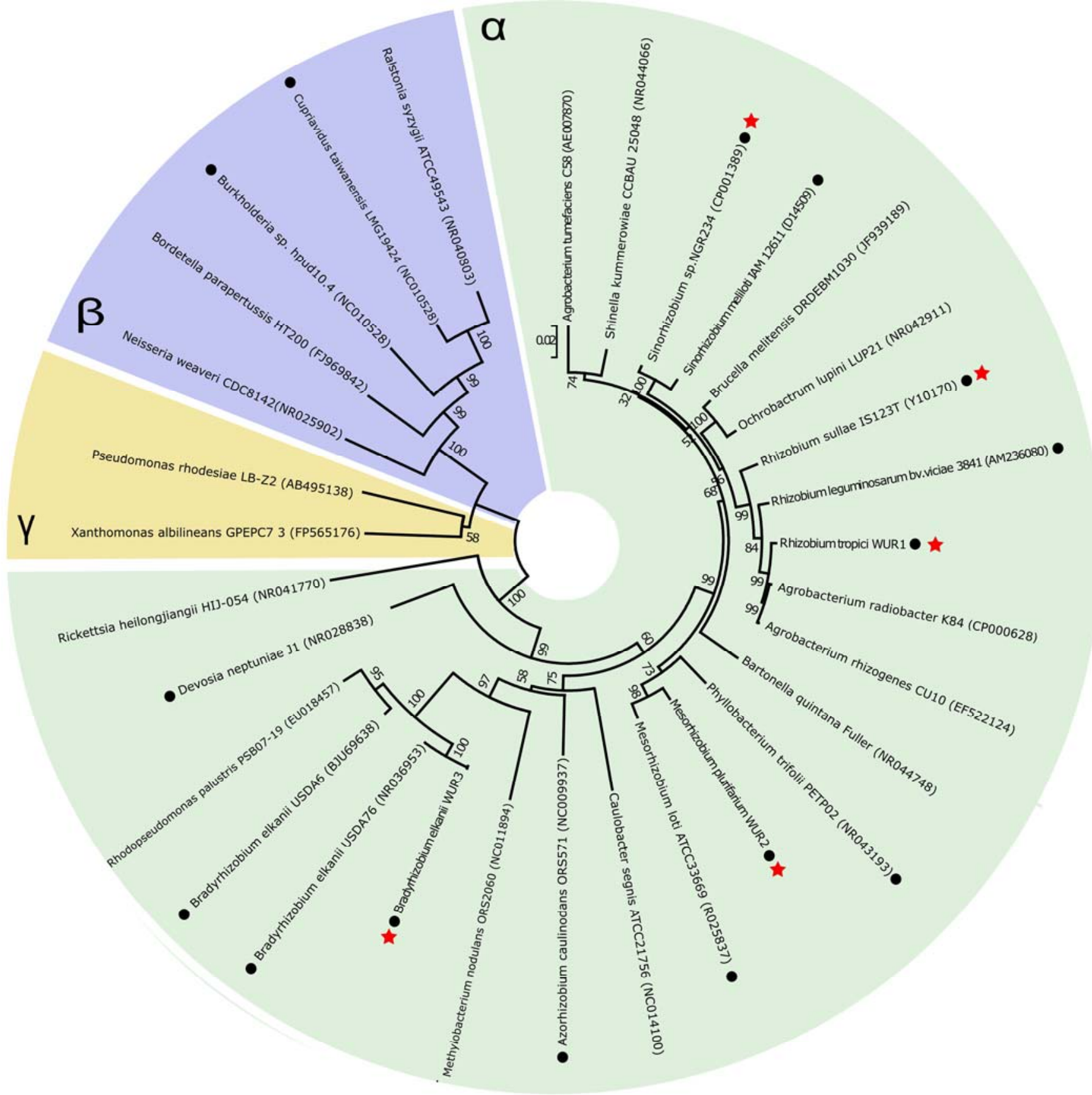

Fig. 1. Unrooted phylogenetic tree of $16 \mathrm{~S}$ rRNA gene sequences from selected $\alpha$-, $\beta$-, and $\gamma$-proteobacteria. Reconstructed with the neighbor-joining method implemented in the software package MEGA5. Branch support is obtained from 1,000 bootstrap repetitions. Genera marked with a black dot contain rhizobia. Stars mark the strains confirmed to nodulate Parasponia andersonii. 
studies do not elucidate whether such a protein can use Nod factor precursor molecules as substrate, we annotated the corresponding genes as "nodL-like."

In summary, the enzymes encoded by the nodulation genes in common in the four species compared can produce a basic Nod factor, of which the nonreducing glucosamine residue is $\mathrm{N}$-methylated. Because NodL and NodU were shown to be mutually exclusive, this nonreducing glucosamine is either carbamoylated at carbon C5 or C6 positions or acetylated at the C6 position (López-Lara et al. 2001). In line with this, we postulate that $P$. andersonii recognizes a specific molecule with either only NodS- and possibly NodU- or NodL-based modifications. Alternatively, P. andersonii has a low specificity for Nod factor structure.

\section{Parasponia nodules infected}

with different rhizobia vary in symbiotic efficiency.

Nod factor recognition and subsequent nodule formation does not always lead to an effective nitrogen-fixing symbiosis. It is known that some rhizobia can colonize nodules but lack sufficient nitrogenase activity, resulting in poor fixation (Den Herder and Parniske 2009). To identify the most efficient strain for $P$. andersonii, we conducted a comparative study between the four selected rhizobia. Their symbiotic efficiency was studied by comparing nodule number and rate of nitrogen fixation. We inoculated $P$. andersonii plantlets with either $R$. tropici WUR1, M. plurifarium WUR2, Sinorhizobium sp. strain NGR234, or B. elkanii WUR3. Four weeks after inoculation, the number of nodulated plants, nodule number per plant, and nitrogen-fixation rate were determined (Table 2). The latter was done by using the acetylene reduction assay (Bergersen 1970). B. elkanii WUR3 was found to have the highest nitrogen-fixation rate compared with the other three species. This difference was found to be statistically significant (analysis of variance [ANOVA] test, $P<0.001$ ). However, nodulation efficiency varied largely between the various rhizobium species (Table 2). Sinorhizobium sp. strain NGR234 nodulated only two of nine plantlets, confirming earlier nodulation studies with this strain (Op den Camp et al. 2011; Webster et al. 1995). A comparable efficiency was found for M. plurifarium WUR2, whereas both of the other strains nodulated with almost $100 \%$ efficiency (Table 2 ). The number of nodules varied among the strains tested but was found not to be statistically significant (ANOVA test, $P=0.102$ ) (Table 2). Next, we questioned whether $P$. andersonii profits from the higher nitrogenfixation rate of $B$. elkanii WUR3. Therefore, we compared the shoot weight of $B$. elkanii WUR3 inoculated plantlets with the shoot weight of plantlets inoculated with the least-efficient

Table 1. Nod factor biosynthesis genes in Parasponia-compatible strains ${ }^{\mathrm{a}}$

\begin{tabular}{|c|c|c|c|c|c|}
\hline \multirow[b]{2}{*}{ Factor } & \multirow[b]{2}{*}{ Query } & \multirow[b]{2}{*}{ GenBank } & \multicolumn{3}{|c|}{ Identities/positives (\%) (BLASTP) } \\
\hline & & & $\begin{array}{c}\text { Rhizobium tropici } \\
\text { WUR1 }\end{array}$ & $\begin{array}{c}\text { Mesorhizobium } \\
\text { plurifarium WUR2 }\end{array}$ & $\begin{array}{c}\text { Bradyrhizobium } \\
\text { elkanii WUR3 }\end{array}$ \\
\hline NodA & Sinorhizobium sp. strain NGR234 & АAB91697 & $67 / 82$ & 68/82 & $67 / 79$ \\
\hline NodA2 & $\ldots$ & $\ldots$ & $68 / 81$ & $66 / 82$ & $\ldots$ \\
\hline NodA3 & $\ldots$ & $\ldots$ & $68 / 81$ & $\ldots$ & $\ldots$ \\
\hline NodB & Sinorhizobium sp. strain NGR234 & AAB91696 & $67 / 84$ & $68 / 83$ & $67 / 84$ \\
\hline NodB2 & $\ldots$ & $\ldots$ & $\ldots$ & $65 / 82$ & $\ldots$ \\
\hline NodC & Sinorhizobium sp. strain NGR234 & AAB91695 & 77/84 & 77/84 & 78/86 \\
\hline NodE & R. leguminosarum bv. viciae 3841 & YP770460 & $77 / 86$ & $81 / 90$ & $\ldots$ \\
\hline NodE2 & $\ldots$ & $\ldots$ & $\ldots$ & $73 / 84$ & $\ldots$ \\
\hline NodF & R. leguminosarum bv. viciae 3841 & YP770461 & $52 / 73$ & $59 / 72$ & $\ldots$ \\
\hline NodF2 & $\ldots$ & $\ldots$ & $\ldots$ & $55 / 69$ & $\ldots$ \\
\hline NodH & Sinorhizobium meliloti 1021 & NP435710 & $68 / 78$ & $73 / 82$ & $\ldots$ \\
\hline NodL & R. leguminosarum bv. viciae 3841 & YP765858 & 75/82 & $66 / 76$ & $49 / 59$ \\
\hline NodP & Sinorhizobium sp. strain NGR234 & YP002823393 & 78/87 & 77/88 & $66 / 80$ \\
\hline NodQ & Sinorhizobium sp. strain NGR234 & ACP22641 & 77/87 & $69 / 82$ & $57 / 73$ \\
\hline NodS & Sinorhizobium sp. strain NGR234 & AAB91783 & 71/86 & 70/83 & $71 / 81$ \\
\hline NodU & Sinorhizobium sp. strain NGR234 & AAB91782 & 77/88 & 75/88 & 74/84 \\
\hline NodZ & Sinorhizobium sp. strain NGR234 & AAB91605 & $\ldots$ & $\ldots$ & $73 / 87$ \\
\hline NolL & Sinorhizobium sp. strain NGR234 & AAB91652 & $\ldots$ & $\ldots$ & $56 / 70$ \\
\hline NolO & Sinorhizobium sp. strain NGR234 & AAB91692 & $\ldots$ & $\ldots$ & $77 / 88$ \\
\hline NoeE & Sinorhizobium sp. strain NGR234 & AAB91690 & $\ldots$ & $\ldots$ & $60 / 70$ \\
\hline NoeI & Sinorhizobium sp. strain NGR234 & AAB91691 & $\ldots$ & $\ldots$ & $72 / 87$ \\
\hline
\end{tabular}

a Given are the percentage of identity and positives on the basis of BLASTP. As query homologous, proteins of Sinorhizobium sp. strain NGR234 are used, with the exception of NodE, NodF, NodL, and NodH, for which proteins of Rhizobium leguminosarum bv. viciae 3841 or Sinorhizobium meliloti 1021 were used. Genes in common are highlighted in bold.

Table 2. Symbiotic efficiency of rhizobia with the hosts Parasponia andersonii, cowpea, lotus, and groundnut ${ }^{\mathrm{a}}$

\begin{tabular}{|c|c|c|c|c|}
\hline Plant species & Bacterial strain & Fraction nodulated plants & Number of nodules/plant & $\operatorname{ARA}\left(\mu \mathrm{mol} \mathrm{C} \mathrm{C}_{2} \mathrm{H}_{4} / \mathrm{h} / \mathrm{g} \mathrm{fw}\right)$ \\
\hline \multirow[t]{4}{*}{ Parasponia andersonii } & Rhizobium tropici WUR1 & $12 / 14$ & $5.7 \pm 4.6$ & $0.29 \pm 0.17$ \\
\hline & Sinorhizobium sp. strain NGR234 & $2 / 9$ & $5.4 \pm 4.3$ & $0.52 \pm 0.30$ \\
\hline & Mesorhizobium plurifarium WUR2 & $2 / 15$ & $10.7 \pm 1.2$ & $0.84 \pm 0.75$ \\
\hline & Bradyrhizobium elkanii WUR3 & $14 / 14$ & $9.8 \pm 6.2$ & $2.88 \pm 1.39 *$ \\
\hline \multirow{2}{*}{ Vigna unguiculata } & Rhizobium tropici WUR1 & $15 / 15$ & $21.3 \pm 5.3$ & $0.91 \pm 0.51$ \\
\hline & Sinorhizobium sp. strain NGR234 & $15 / 15$ & $27.7 \pm 10.0$ & $1.29 \pm 0.66$ \\
\hline \multirow[t]{2}{*}{ Lotus japonicus } & Rhizobium tropici WUR1 & $10 / 15$ & $1.6 \pm 1.7$ & ND \\
\hline & Sinorhizobium sp. NGR234 & $13 / 15$ & $6.0 \pm 4.1$ & $0.01 \pm 0.02$ \\
\hline \multirow{2}{*}{ Arachis hypogaea } & Rhizobium tropici WUR1 & $0 / 15$ & ND & ND \\
\hline & Sinorhizobium sp. strain NGR234 & $10 / 12$ & $18.0 \pm 13.2$ & ND \\
\hline
\end{tabular}

${ }^{a}$ Data from 4 weeks after inoculation for each strain. Nitrogen fixation was measured with the acetylene-reduction assay (ARA) and expressed as micromoles of $\mathrm{C}_{2} \mathrm{H}_{4}$ per hour per gram fresh weight (fw) of nodule. Errors represent \pm standard deviation. ND = not detected. Asterisk marks statistical significant difference between $B$. elkanii WUR3 and the other three strains (analysis of variance, $P \leq 0.001$ ). 
nitrogen-fixing strain, $R$. tropici WUR1. Plants inoculated with the best nitrogen-fixing strain generated a significantly higher shoot weight 4 weeks postinoculation; $B$. elkanii WUR3 with $0.122 \pm 0.055 \mathrm{~g}$ versus $R$. tropici WUR1 with $0.040 \pm 0.018 \mathrm{~g}$ ( $t$ test, $P<0.001$ ). Therefore, we conclude that $B$. elkanii WUR3 is an efficient symbiotic partner for $P$. andersonii.

\section{R. tropici WUR1 triggers cell death in Parasponia root nodules.}

To investigate whether there are cytological differences in effective and ineffective Parasponia nodules, we studied nodule morphology in more detail using light and transmission electron microscopy. Four-week-old nodules infected with either M. plurifarium WUR2, Sinorhizobium NGR234, or B. elkanii WUR3 showed a canonical organization, similar to that described before (Fig. 2A through D; Supplementary Figs. S5 and S6) (Trinick and Galbraith 1976; Webster et al. 1995). In short, nodules resemble modified lateral roots with a central vascular bundle and a peripheral zone of infected cortical cells. From the nodule meristem, cells progress to the infection zone, where rhizobium infection threads penetrate the host cell and persist intracellularly (Fig. 2A). Upon intracellular infection, the vacuole of an infected cortical cell shatters into multiple small vacuoles (Fig. 2B and C). Infection threads undergo a transition to fixation threads, which have a much thinner cell wall but still contain a plant-derived membrane and harbor, at first, a single phylum of rhizobia (Op den Camp et al. 2011). In older cells, toward to the base of the nodule, these fixation threads completely fill the host cell and encompass up to four phyla of rhizobia (Fig. 2D). This zone of filled cells stretches out for over 20 cell layers and is the zone where actual nitrogen fixation is occurring (Fig. 2A).

$R$. tropici WUR1-infected nodules differed from nodules infected with any of the other three species because the number of cells that contained fixation threads stretch only for one to three layers close to the meristem of the nodule. More basal cells are completely filled with bacteria embedded in a dense matrix (Fig. 2E through G). These structures are possibly the result of continuous growth and fusion of infection threads, thereby pushing aside the host cytoplasm (Fig. 2H). Ultimately, this leads to cells that are completely devoid of cytoplasm, causing the death of the host cell. Rhizobia persist, encapsulated in a matrix inside these dead plant cells (Fig. 2G and I). These fully colonized cells are surrounded by noninfected cells with a normal cytoarchitecture (Fig. 2I). Occasionally, similar dead cells have been observed in functional nodules colonized by Sinorhizobium sp. strain NGR234, M. plurifarium WUR2, and $B$. elkanii WUR3. Still, these cells were never as abundant and in such young layers of the fixation zone as those found for $R$. tropici WUR1.

We questioned whether $R$. tropici WUR1 could still fix nitrogen in the encapsulated state. Therefore, we transformed $R$. tropici WUR1 with an nifH promoter green fluorescent protein (GFP) reporter construct (pSm_nifHp::GFP) to monitor transcriptional regulation of nitrogenase. By monitoring GFP fluorescence in $P$. andersonii nodules induced by this tagged strain, it was found that nifH expression continued in the matrix-encapsulated form (Supplementary Fig. S7). The processing of GFP also implies that these encapsulated rhizobia are still metabolically active.

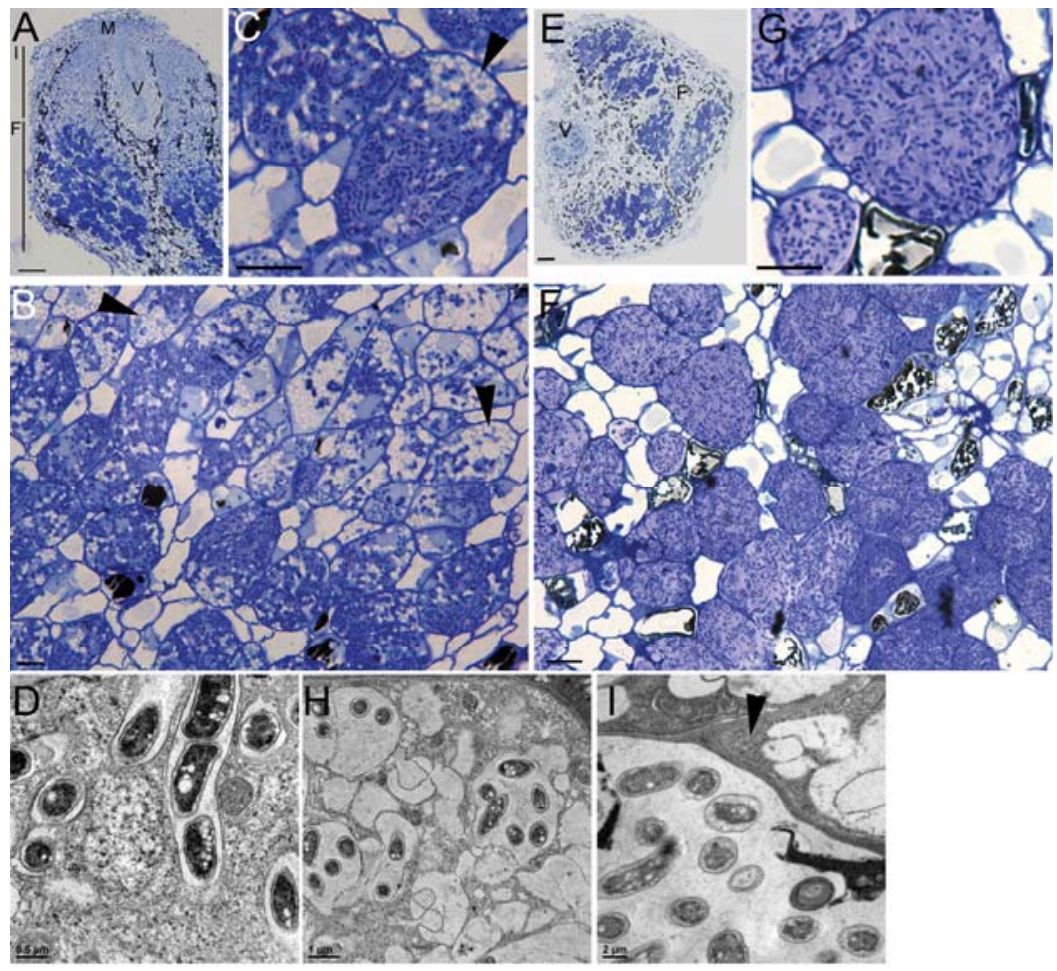

Fig. 2. Parasponia andersonii nodule structure after inoculation with A through D, Sinorhizobium sp. strain NGR234 and E to I, Rhizobium tropici strain WUR1. A to C, Approximately 1- $\mu$ m-thin resin-embedded sections of a Sinorhizobium sp. strain NGR234 nodule. A, Single lobe; central vascular bundle (V), nodule meristem (M), infection zone (I), and fixation zone (F). B, Cells on the border of infection and fixation zone; examples of shattered vacuoles are marked with arrowheads. C, Detail of B; cell almost completely filled with fixation threads, shattered vacuole is marked with arrowhead. D, Transmission electron microscope (TEM) image of fixation threads filled with rhizobia. E to G, Approximately 1- $\mu$ m-thin resin-embedded sections of a Rhizobium tropici WUR1 nodule. E, Cross-section through the vascular bundle (V) and fixation zone (F) of a nodule. F, Cells of fixation zone, with rhizobia in light-purplestained dense matrix inside dead nodule cells. G, Detail of F; large dead infected cell with rhizobia in light-purple-stained dense matrix surrounded by noninfected living cells. H, TEM image of fusing and disintegrating fixation threads with $>4$ fila of rhizobia. I, TEM image of a dead fixation zone cell as shown in $\mathrm{G}$, filled with living rhizobia. Surrounding two cells have normal cytoplasm, as marked with the arrowhead. Bars: A and E, $100 \mu \mathrm{m}$; B and $\mathrm{C}, 10 \mu \mathrm{m}$; F and $\mathrm{G}, 25 \mu \mathrm{m} ; \mathrm{D}, 0.5 \mu \mathrm{m} ; \mathrm{H}, 1 \mu \mathrm{m} ; \mathrm{I}, 2 \mu \mathrm{m}$. 


\section{$R$. tropici WUR1 can establish an efficient symbiosis with cowpea and lotus.}

The results obtained with $R$. tropici WUR1 on $P$. andersonii made us question whether the parasitic nature of the interaction is an intrinsic character of this strain or the result of incompatibly with this specific host plant. To discriminate between these two hypotheses, we tested the symbiotic capacity of $R$. tropici WUR1 on different legume host plants. To this end, we selected Vigna unguiculata (cowpea) because it generally is considered to be highly promiscuous, Arachis hypogaea (groundnut) because it is infected by crack entry, and the model legume Lotus japonicus (lotus) (Boogerd and van Rossum 1997; Lewin et al. 1987; Pajuelo and Stougaard 2005; Perret et al. 2000; Witzany 2011). As positive control, we inoculated these legumes with Sinorhizobium sp. strain NGR234, which is known to nodulate all three species (Pueppke and Broughton 1999).

Sinorhizobium sp. strain NGR234 nodulated all three legumes, although with different efficiencies (Table 2). Sinorhizobium sp. strain NGR234-infected cowpea nodules displayed a canonical cytoarchitecture and fixed nitrogen most efficiently (Table 1; Fig. 3A and B). In contrast, nodules on lotus and groundnut were less effective, which is in line with previous reports (Fig. 3E, F, I, and J; Table 2) (Pueppke and Broughton 1999; Schumpp et al. 2009; Wong and Patchamuthu 1988). $R$. tropici WUR1 was found to nodulate both cowpea and lotus but not groundnut (Table 2). On lotus, nodulation was less efficient, though the few nodules formed had a normal cytoarchitecture, including well-developed symbiosomes in infected cells (Table 2; Fig. 3G and $\mathrm{H}$ ). Due to the very low nodule number per plant, the nitrogen-fixation rate was beyond the detection limit of our experimental setup. In the case of cowpea, nodules were found to fix nitrogen at a similar rate compared with Sinorhizobium sp. strain NGR234-infected nodules. Sections of $R$. tropici WUR1-infected nodules revealed a very similar structure compared with infected Sinorhizobium sp. strain NGR234 nodules (Fig. 3C and D). Taken together, these results show that $R$. tropici WUR1 can establish an effective endosymbiosis with legumes. Therefore, we conclude that the aberrant termination of symbiosis as observed after intracellular colonization by $R$. tropici WUR 1 in $P$. andersonii is the result of host incompatibility.

\section{DISCUSSION}

We showed that $P$. andersonii is highly promiscuous for rhizobia, because it can be nodulated by bacteria from four different genera. Rhizobial engagement in the non-leguminous genus Parasponia is most likely a far more recent evolutionary event compared with legumes; therefore, we argue that high promiscuity is the basal state of rhizobial host plants. A possible drawback of this high promiscuity is that low-efficient strains can infect nodules as well, which is underlined by the finding that $P$. andersonii host strains display a range in nitrogen-fixation effectiveness.

The rhizobial strains studied here display diversity in nodulation genes, suggesting that $P$. andersonii either recognizes Nod factors with a range of decorations or, alternatively, recognizes a very basal Nod factor structure that all four strains have in common. $R$. tropici WUR1 and $M$. plurifarium WUR2 harbor a similar set of nod genes. The presence of the sulfotransferase $n o d H$ as well as the sulfate adenylyltransferase encoded by nodPQ suggests that both species produce sulfated Nod factors. In the case of other $R$. tropici strains, such sulfated Nod factors have, indeed, been characterized (Estévez et al. 2009; Folch-Mallol et al. 1996; Morón et al. 2005). However, because nodH is lacking in Sinorhizobium sp. strain
NGR234 and B. elkanii WUR3, it suggests that Nod factor sulfation is not essential to infect $P$. andersonii. Alternatively, the lack of $n o d H$ is functionally complemented by noeE, which encodes a fucose-specific sulfotransferase (Perret et al. 2000). However, Nod factors that are solely sulfated at the reducing glucosamine terminal residue have not been found in Sinorhizobium sp. strain NGR234 or in Bradyrhizobium spp., making
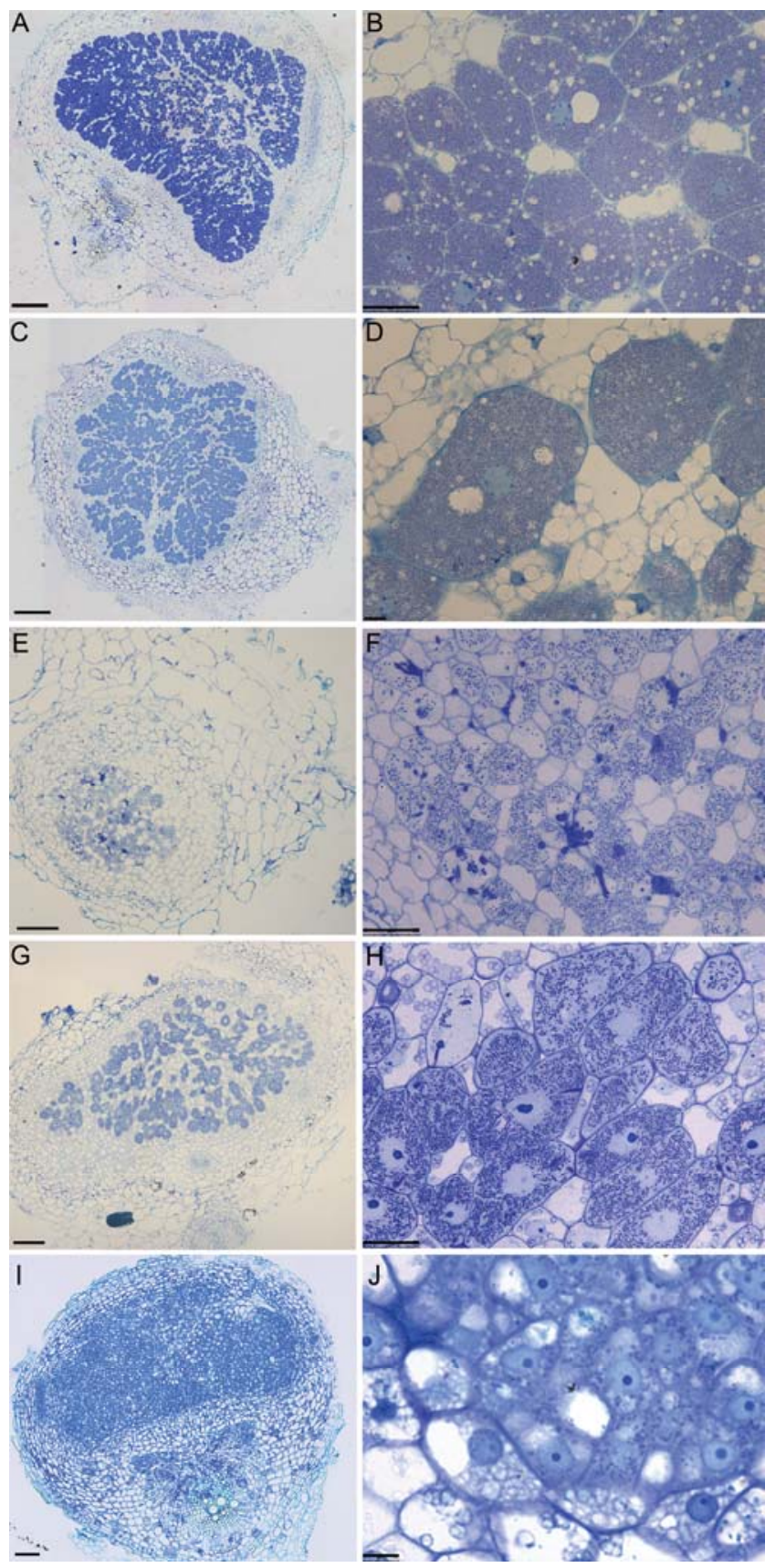

Fig. 3. Legume nodule structure after inoculation of Sinorhizobium sp. strain NGR234 and Rhizobium tropici strain WUR1. Approximately 3- $\mu$ mthin resin-embedded sections. A, Cross-section of a cowpea Sinorhizobium sp. strain NGR234 nodule. B, Detail of cowpea host cells filled with Sinorhizobium sp. strain NGR234 symbiosomes. C, Cross-section of a cowpea $R$. tropici WUR1 nodule. D, Detail of cowpea host cells filled with $R$. tropici WUR1 symbiosomes. E, Cross-section of a lotus Sinorhizobium $\mathrm{sp}$. strain NGR234 nodule. F, Detail of lotus host cells filled with Sinorhizobium sp. strain NGR234 symbiosomes. G, Cross-section of a lotus $R$. tropici WUR1 nodule. H, Detail of lotus host cells filled with $R$. tropici WUR1 symbiosomes. I, Cross-section of a groundnut Sinorhizobium sp. strain NGR234 nodule. J, Detail of groundnut host cells filled with Sinorhizobium sp. strain NGR234 symbiosomes. 
such hypothesis unlikely (D'Haeze and Holsters 2002; Price et al. 1992). Considering that B. elkanii WUR3 and Sinorhizobium sp. strain NGR234 also do not possess an nodEF operon, which is known to contribute variation in the Nod factor attached acyl chain, one could speculate that the minimum nod gene set essential to nodulate Parasponia spp. consists of only $\operatorname{nod} A, \operatorname{nod} B, \operatorname{nod} C$, nodS, and $\operatorname{nod} U$. The Nod factor produced by such a minimal gene set would be very basic and structurally closely related to Myc Factors, with a possible structural variation at a nonreducing terminal glucosamine residue (Maillet et al. 2011). This residue can be N-methylated due to activity of methyltransferase NodS, whereas carbon C6 of this residue can be either carbamoylated or acetylated due to activity of carbamoyl transferase NodU and acetyl transferase NodL.

It is conceivable that the line between recognizing Nod factors or Myc factors in Parasponia spp. is very fine. We hypothesize that, due to the young age of its rhizobium symbiosis, Parasponia Nod factor receptors did not coevolve with rhizobia and, therefore, did not diverge from mycorrhizal recognition to develop specificity for the Nod factor. This hypothesis is in line with our previous finding that a single Nod factor receptor, PaNFP, controls both symbioses in $P$. andersonii (Op den Camp et al. 2011). A consequence of this hypothesis is that the read-out of the Nod- or Myc-factor signaling pathway may be determined by the physiological condition of the host plant (e.g., $\mathrm{N}$ or P status).

Like Parasponia spp., there are also legume species that display promiscuity to many rhizobial species, of which siratro (Macroptilium atropurpureum), dolichos (Lablab purpureus) Phaseolus spp., and cowpea (V. unguiculata) are well known examples (Perret et al. 2000). Symbiotic promiscuity is dispersed in the legume family. In line with our data in the genus Parasponia, it was argued that in legumes, also, a high promiscuity could reflect the ground state of the rhizobium symbiosis (Perret et al. 2000). Because promiscuous legumes still exist today, it suggests that these have not been under selection for host specificity.

For Parasponia spp., a possible drawback of being very promiscuous can be that promiscuity grants access to inefficient rhizobium strains. We showed that the nitrogen-fixation rate varies greatly among the different microsymbionts. Still, some legumes with a reputed high specificity can be infected by underperforming rhizobia as well (Terpolilli et al. 2008; Torres Tejerizo et al. 2011). However, legumes have an additional strategy to prevent underperforming microsymbionts; namely, premature nodule senescence. In legumes, this host-plant-controlled process actively ends the symbiosis due to fusions of lytic vesicles to symbiosomes (Limpens et al. 2009). As a result, the microsymbionts are actively degraded and, ultimately, the host cell dies as well (Van de Velde et al. 2006). Senescence normally only occurs when nodules mature, which is also reported for Parasponia spp. (Puppo et al. 2005; Trinick 1979). However, when rhizobia are underperforming either by host incompatibility or by loss-of-function mutations, this mechanism can be triggered prematurely in legumes (Hirsch and Smith 1987; Van de Velde et al. 2006). We did not observe premature nodule senescence in the case of $P$. andersonii nodules that are colonized by the ineffective $R$. tropici WUR 1 . In contrast, the rhizobia are not lysed by the plant and even remained metabolically active. A similar phenotype was reported previously (Trinick et al. 1989). Taken together, this suggests that Parasponia spp. have not yet evolved a mechanism to control underperforming host strains. This implies that Parasponia plants may not be entirely in control over the situation inside a nodule. In contrast, for legumes, it has been shown that they can impose sanctions against underperforming strains (Kiers et al. 2003). We hypothesize that, due to the young age of the Parasponia symbiosis, sanctions against underperforming microsymbionts are not yet effective. Therefore, there may be a delicate balance between mutual benefits and parasitic colonization in the case of such underperforming rhizobia that colonize Parasponia spp.

\section{MATERIALS AND METHODS}

\section{Rhizobium strains.}

WUR strains isolated from nodules on $P$. andersonii trees grown in potting soil of mixed European origin were $R$. tropici WUR1 and Mesorhizobium plurifarium WUR2; and, from nodules on $C$. fasiculata, B. elkanii WUR3 was isolated. Furthermore, we used Sinorhizobium sp. strain NGR234 and $R$. sullae IS123T (Price et al. 1992; Squartini et al. 2002). $R$. tropici WUR1 was transformed with a modified pHC60 plasmid now harboring pSm_nifHp::GFP (Op den Camp et al. 2011).

\section{Sequencing.}

DNA was isolated from rhizobium liquid cultures. Cultures were lysed and washed, the chloroform/phenol was extracted, and the ethanol-precipitated DNA was purified using a Qiagen DNeasy blood and tissue kit according to the manufacturer's protocol (Qiagen, Hilden, Germany). DNA was sequenced with a paired end run on an Illumina Genome Analyzer II (Illumina Inc., San Diego, CA, U.S.A.) platform. Quality trimmed reads were assembled using CLC Genomics Workbench software (CLC Bio, Aarhus, Denmark). This resulted in $21 \times 10^{6}$ paired reads for $R$. tropici WUR1, with an average length of 223 nucleotides (nt); $16 \times 10^{6}$ paired reads for $M$. plurifarium WUR2, with an average length of $218 \mathrm{nt}$; and $33 \times$ $10^{6}$ paired reads for $B$. elkanii WUR3, with an average length of $244 \mathrm{nt}$. The approximate total genome sizes based on the sum of all assembled contigs were $6.6 \mathrm{MB}$ for $R$. tropici WUR1 (116 contigs, average length $58 \mathrm{~kb}$ ), 7.2 MB for $M$. plurifarium WUR2 (82 contigs, average length $87 \mathrm{~kb}$ ), and 8.3 MB for B. elkanii WUR3 (184 contigs, average length $45 \mathrm{~kb}$ ). Genes were predicted using FGENESB (Softberry, Mount Kisco, NY, U.S.A.), BASys (Van Domselaar et al. 2005), and manual annotation. Estimated full-length 16S rDNA and genes encoding proteins involved in Nod-factor biosynthesis were identified by BLAST searches. Their sequences were submitted to GenBank (accession numbers JQ889855 to JQ889866). The Artemis genome browser was used to view and edit the data (Rutherford et al. 2000). Sequences used from Sinorhizobium sp. strain NGR234 were obtained from the National Center for Biotechnology Information database under BioProject PRJNA59081.

\section{Plant materials.}

Clonally propagated $P$. andersonii WU1 plantlets were used in all nodulation assays (Op den Camp et al. 2011). Lotus japonicus Gifu seeds were sterilized by soaking them in sulfuric acid for $3 \mathrm{~min}$, followed by six washes with water and $7 \mathrm{~min}$ in $4 \%$ commercial bleach, again followed by six washing steps with sterile water. Seeds were then put on agar plates to allow germination. After germination, seedlings were grown on Fåhraeus medium for 1 week before transfer to the greenhouse (Fåhraeus 1957). Seed from V. unguiculata or A. hypogaea were used for nodulation assays without pre-treatment.

\section{Nodulation assay.}

All plants were grown on an autoclaved 1:1 mixture of 1- to 2-mm diameter hydrogranules and fine sand, watered weekly with EKM medium (Becking 1983). P. andersonii plantlets 
were inoculated directly after transfer from tissue culture whereas $V$. unguiculata and A. hypogaea seeds were first germinated and grown for 3 days in the greenhouse before inoculation. L. japonicus seeds were germinated in vitro and 1-weekold plants were transferred to the greenhouse and inoculated. All plants were inoculated with $2 \mathrm{ml}$ of liquid culture of a rhizobium strain (optical density at $600 \mathrm{~nm}=0.1$ ). Inoculated plants were grown for 4 weeks in a conditioned greenhouse at $28^{\circ} \mathrm{C},>85 \%$ humidity, and 16 and $8 \mathrm{~h}$ of artificial light and darkness, respectively. Only L. japonicus plants were grown for 4 weeks in a conditioned greenhouse at $20^{\circ} \mathrm{C},<70 \%$ humidity, and 16 and $8 \mathrm{~h}$ of artificial light and darkness, respectively. The four rhizobium strains tested were reisolated as described below from several independent nodules for all inoculations, and identity of the isolates was confirmed by sequencing their 16S rRNA genes.

\section{Isolation of rhizobium strains from nodules.}

The selected nodules were surface sterilized in $96 \% \mathrm{EtOH}$ for $20 \mathrm{~s}$ followed by $4 \%$ sodium hypochlorite for $6 \mathrm{~min}$ (reduced to $4 \mathrm{~min}$ in the case of small nodules). Finally, the nodules were washed seven times with sterile distilled water. Each nodule was squashed in 20 to $100 \mu \mathrm{l}$ of $0.9 \% \mathrm{NaCl}$ solution, the volume varying in proportion to the nodule size. The suspension was serially diluted and streaked on yeast-mannitol agar plates, and these were incubated at $28^{\circ} \mathrm{C}$.

\section{Strain characterization.}

Cells were lysed by resuspending a loopful of plate-grown isolated colonies in $50 \mu \mathrm{l}$ of lysis buffer $(0.25 \%$ sodium dodecyl sulfate and $0.05 \mathrm{M} \mathrm{NaOH}$ ), followed by stirring for $60 \mathrm{~s}$ on a vortex and heating at $95^{\circ} \mathrm{C}$ for $15 \mathrm{~min}$. The lysate was centrifuged for $15 \mathrm{~min}$ and $10 \mu \mathrm{l}$ of the supernatant was mixed with $90 \mu \mathrm{l}$ of sterile water. The lysate $(1 \mu \mathrm{l})$ was used for polymerase chain reaction (PCR) amplification of the $16 \mathrm{~S}$ rRNA gene region using the universal bacterial primers $63 \mathrm{~F}\left(5^{\prime} \mathrm{CAGGCC}\right.$ TAACACATGCAAGTC) (Marchesi et al. 1998) and 1389R (5' ACGGGCGGTGTGTACAAG) (Osborn et al. 2000). PCR products were Sanger sequenced and analyzed using the DNASTAR software package (DNASTAR, Madison, WI, U.S.A.).

\section{Acetylene reduction assay.}

Nitrogen fixation was measured by the acetylene reduction assay (Bergersen 1970). The root system $(n=15)$ was washed free of sand, separated from the shoot, and put in a $10-\mathrm{ml}$ vial for $P$. andersonii and L. japonicus. For $V$. unguiculata and A. hypogaea, a $35-\mathrm{ml}$ vial was used instead. The humidity was preserved during the test by adding some wet tissue paper to the vial. The vials were sealed with rubber stoppers and $10 \%$ of air was withdrawn from each vial and replaced with acetylene. After $1 \mathrm{~h}$ of incubation, $0.2 \mathrm{ml}$ of headspace gas was drawn from each sample and injected into a ChromPack gas chromatograph equipped with a Porapak R column (80 to 100 mesh; 2-by-2-mm i.d.) and a flame ionization detector (Varian ChromPack; Bergen Op Zoom, The Netherlands). Nitrogen was used as carrier gas at $20 \mathrm{ml} / \mathrm{min}$. Statistical analysis was performed using the SigmaStat software package (Systat Software, San Jose, CA, U.S.A.).

\section{Histology and microscopy.}

Fixation of roots was performed for $24 \mathrm{~h}$ at $40^{\circ} \mathrm{C}$ in $5 \%$ glutaraldehyde (vol/vol) and 3\% sucrose (wt/vol) dissolved in phosphate buffer ( $\mathrm{pH}$ 7.0). Subsequently, an ethanol dehydration series was carried out. The completely dehydrated roots were embedded in Technovit 7100 (Heraeus-Kulzer, Wehrheim, Germany) according to the manufacturers protocol. Microtome sections of 3 to $5 \mu \mathrm{m}$ were stained with toluidine blue and photographed using a Leica DM5500B microscope equipped with a DFC425C camera (Leica Microsystems B.V., Wetzlar, Germany). Images were digitally processed using Photoshop CS3 (Adobe Systems, San Jose, CA, U.S.A.). For transmission electron microscopy and for the images in Figures 2 and $3 \mathrm{~F}$ and $\mathrm{H}$, nodules were processed as described by Wang and associates (2010). For confocal microscopy, fresh hand-sectioned nodule cuttings were stained with FM-64 and imaged with a Zeiss LSM 510 confocal laser scanning microscope (Carl-Zeiss, Oberkochen, Germany), excitation 488 nm (GFP) and $543 \mathrm{~nm}$ (FM-64); GFP emission was selectively detected by using a $505 \pm 530$-nm band pass filter and FM-64 emission was detected in another channel using a $560 \pm 615-\mathrm{nm}$ band pass filter.

\section{Phylogenetic analysis.}

The phylogenetic tree in Figure 1 was reconstructed using the neighbor-joining method implemented in the software MEGA5 (Tamura et al. 2011). Alignment of >1,200-bp-long 16S rRNA gene sequences was used for tree building. Reference sequences were retrieved from the Ribosomal Database Project (Cole et al. 2009). Default settings were used and branch support was obtained from 1,000 bootstrap repetitions.

\section{ACKNOWLEDGMENTS}

This work was supported by the Dutch Science Foundation (NWO) VIDI 864.06.007 to R. Geurts and the Russian Federation Basic Research grant for Centre of Excellence 047.018.001 to E. Fedorova. We thank Prof. E. C. Cocking for sending original stocks of Rhizobium sp. strains CP279 and CP283.

\section{LITERATURE CITED}

Ardourel, M., Demont, N., Debelle, F., Maillet, F., de Billy, F., Prome, J. C., Denarie, J., and Truchet, G. 1994. Rhizobium meliloti lipooligosaccharide nodulation factors: Different structural requirements for bacterial entry into target root hair cells and induction of plant symbiotic developmental responses. Plant Cell 6:1357-1374.

Arrighi, J. F., Barre, A., Ben Amor, B., Bersoult, A., Soriano, L. C., Mirabella, R., de Carvalho-Niebel, F., Journet, E. P., Gherardi, M., Huguet, T., Geurts, R., Denarie, J., Rouge, P., and Gough, C. 2006. The Medicago truncatula lysin motif-receptor-like kinase gene family includes NFP and new nodule-expressed genes. Plant Physiol. 142:265-279.

Becking, J. H. 1983. The Parasponia parviflora-Rhizobium symbiosishost specificity, growth and nitrogen-fixation under various conditions. Plant Soil 75:309-342.

Becking, J. H. 1992. The rhizobium symbiosis of the nonlegume Parasponia. Pages 497-559 in: Biological Nitrogen Fixation. G. Stacey, R. H. Burris, and H. J. Evans, eds. Chapman and Hall, New York.

Bergersen, F. 1970. The quantitative relationship between nitrogen fixation and the acetylene-reduction assay. Aust. J. Biol. Sci. 23:1015-1026.

Bloemberg, G. V., Thomas-Oates, J. E., Lugtenberg, B. J., Spaink, H. P. 1994. Nodulation protein NodL of Rhizobium leguminosarum $O$-acetylates lipo-oligosaccharides, chitin fragments and $\mathrm{N}$-acetylglucosamine in vitro. Mol Microbiol. 4:793-804.

Boogerd, F. C., and van Rossum, D. 1997. Nodulation of groundnut by Bradyrhizobium: A simple infection process by crack entry. FEMS (Fed. Eur. Microbiol. Soc.) Microbiol. Rev. 21:5-27.

Capoen, W., Goormachtig, S., and Holsters, M. 2010. Water-tolerant legume nodulation. J. Exp. Bot. 61:1251-1255.

Charpentier, M., and Oldroyd, G. 2010. How close are we to nitrogen-fixing cereals? Curr. Opin. Plant Biol. 13:556-564.

Cole, J. R., Wang, Q., Cardenas, E., Fish, J., Chai, B., Farris, R. J., KulamSyed-Mohideen, A. S., McGarrell, D. M., Marsh, T., Garrity, G. M., and Tiedje, J. M. 2009. The Ribosomal Database Project: Improved alignments and new tools for rRNA analysis. Nucleic Acids Res. 37:D141145.

Debellé, F., Plazanet, C., Roche, P., Pujol, C., Savagnac, A., Rosenberg, C., Promé, J. C., and Dénarié J. 1996. The NodA proteins of Rhizobium meliloti and Rhizobium tropici specify the N-acylation of Nod factors by different fatty acids. Mol. Microbiol. 22:303-314.

Den Herder, G., and Parniske, M. 2009. The unbearable naivety of legumes in symbiosis. Curr. Opin. Plant Biol. 12:491-499. 
D'Haeze, W., and Holsters, M. 2002. Nod factor structures, responses, and perception during initiation of nodule development. Glycobiology 12:79R-105R

Downie, J. A. 2010. The roles of extracellular proteins, polysaccharides and signals in the interactions of rhizobia with legume roots. FEMS (Fed. Eur. Microbiol. Soc.) Microbiol. Rev. 34:150-170.

Estévez, J., Soria-Díaz, M. E., de Córdoba, F. F., Morón, B., Manyani, H., Gil, A., Thomas-Oates, J., Van Brussel, A. A. N., Dardanelli, M. S., Sousa, C., and Megías, M. 2009. Different and new Nod factors produced by Rhizobium tropici CIAT899 following Na+ ${ }^{+}$stress. FEMS (Fed. Eur. Microbiol. Soc.) Microbiol. Lett. 293:220-231.

Fahraeus, G. 1957. The infection of clover root hairs by nodule bacteria studied by a simple glass slide technique. J. Gen. Microbiol. 16:374381

Folch-Mallol, J. L., Marroqui, S., Sousa, C., Manyani, H., López-Lara, I. M., van der Drift, K. M., Haverkamp, J., Quinto, C., Gil-Serrano, A., Thomas-Oates, J., Spaink, H. P., and Megías, M. 1996. Characterization of Rhizobium tropici CIAT899 nodulation factors: The role of nodH and nodPQ genes in their sulfation. Mol. Plant-Microbe Interact. 9:151-163.

Goormachtig, S., Capoen, W., James, E. K., and Holsters, M. 2004. Switch from intracellular to intercellular invasion during water stress-tolerant legume nodulation. Proc. Natl. Acad. Sci. U.S.A. 101:6303-6308.

Heath, K. D., and Tiffin, P. 2007. Context dependence in the coevolution of plant and rhizobial mutualists. Proc. Biol. Sci. 274:1905-1912.

Hirsch, A. M., and Smith, C. A. 1987. Effects of Rhizobium meliloti nif and fix mutants on alfalfa root nodule development. J. Bacteriol. 169:1137-1146.

Kaneko, T., Nakamura, Y., Sato, S., Asamizu, E., Kato, T., Sasamoto, S., Watanabe, A., , Idesawa, K., Ishikawa, A., Kawashima, K., Kimura, T., Kishida, Y., Kiyokawa, C., Kohara, M., Matsumoto, M., Matsuno, A., Mochizuki, Y., Nakayama, S., Nakazaki, N., Shimpo, S., Sugimoto, M., Takeucki, C., Yamada, M., and Tabata, S. 2000. Complete genome structure of the nitrogen-fixing symbiotic bacterium Mesorhizobium loti. DNA Res. 7:331-338.

Kaneko, T., Nakamura, Y., Sato, S., Minamisawa, K., Uchiumi, T., Sasamoto, S., Watanabe, A., Idesawa, K., Iriguchi, M., Kawashima, K., Kohara, M., Matsumoto, M., Shimpo, S., Tsuruoka, H., Wada, T., Yamada, M., and Tabata, S. 2002. Complete genomic sequence of nitrogen-fixing symbiotic bacterium Bradyrhizobium japonicum USDA110. DNA Res. 9:189-197.

Kiers, E. T., Rousseau, R. A., West, S. A., and Denison, R. F. 2003. Host sanctions and the legume-rhizobium mutualism. Nature 425:78-81.

Kouchi, H., Imaizumi-Anraku, H., Hayashi, M., Hakoyama, T., Nakagawa, T., Umehara, Y., Suganuma, N., and Kawaguchi, M. 2010. How many peas in a pod? Legume genes responsible for mutualistic symbioses underground. Plant Cell Physiol. 51:1381-1397.

Laeremans, T., Caluwaerts, I., Verreth, C., Rogel, M. A., Vanderleyden, J., and Martínez-Romero, E. 1996. Isolation and characterization of Rhizobium tropici Nod factor sulfation genes. Mol. Plant-Microbe Interact. 9:492-500.

Lewin, A., Rosenberg, C., Meyer, H. A., A, Z., Wong, C. H., Nelson, L., Manen, J. F., Stanley, J., Dowling, D. N., Denarie, J., and Broughton, W. J. 1987. Multiple host-specificity loci of the broad host-range Rhizobium sp. NGR234 selected using the widely compatible legume Vigna unguiculata. Plant Mol. Biol. 8:447-459.

Limpens, E., Franken, C., Smit, P., Willemse, J., Bisseling, T., and Geurts, R. 2003. LysM domain receptor kinases regulating rhizobial Nod factor-induced infection. Science 302:630-633.

Limpens, E., Ivanov, S., van Esse, W., Voets, G., Fedorova, E., and Bisseling, T. 2009. Medicago $\mathrm{N}_{2}$-fixing symbiosomes acquire the endocytic identity marker Rab7 but delay the acquisition of vacuolar identity. Plant Cell 21:2811-2828.

López-Lara, I M, Kafetzopoulos, D., Spaink, H. P., and Thomas-Oates, J. E. 2001. Rhizobial NodL O-acetyl transferase and NodS N-methyl transferase functionally interfere in production of modified Nod factors. J. Bacteriol. 183:3408-3416.

Madsen, L. H., Tirichine, L., Jurkiewicz, A., Sullivan, J.T ., Heckmann, A B., Bek, A. S., Ronson, C. W., James, E. K., and Stougaard, J. 2010. The molecular network governing nodule organogenesis and infection in the model legume Lotus japonicus. Nat. Commun. 1, article number 10. doi:10.1038/ncomms 1009. Published online.

Maillet, F., Poinsot, V., Andre, O., Puech-Pages, V., Haouy, A., Gueunier, M., Cromer, L., Giraudet, D., Formey, D., Niebel, A., Martinez, E. A., Driguez, H., Becard, G., and Denarie, J. 2011. Fungal lipochitooligosaccharide symbiotic signals in arbuscular mycorrhiza. Nature 469:5863.

Marchesi, J. R., Sato, T., Weightman, A. J., Martin, T. A., Fry, J. C., Hiom, S. J., Dymock, D., and Wade, W. G. 1998. Design and evaluation of useful bacterium-specific PCR primers that amplify genes coding for bacterial 16S rRNA. Appl. Environ. Microbiol. 64:795-799.
Martinez-Romero, E. 2009. Coevolution in rhizobium-legume symbiosis? DNA Cell Biol. 28:361-370.

Masson-Boivin, C., Giraud, E., Perret, X., and Batut, J. 2009. Establishing nitrogen-fixing symbiosis with legumes: How many rhizobium recipes? Trends Microbiol. 17:458-466.

Mergaert, P., Van Montagu, M., and Holsters, M. 1997. Molecular mechanisms of Nod factor diversity. Mol. Microbiol. 25:811-817.

Morón, B., Soria-Díaz, M. E., Ault, J., Verroios, G., Noreen, S. Rodríguez-Navarro, D. N., Gil-Serrano, A., Thomas-Oates, J., Megías, M., and Sousa, C. 2005. Low pH changes the profile of nodulation factors produced by Rhizobium tropici CIAT899. Chem. Biol. 12:10291040

Op den Camp, R., Streng, A., De Mita, S., Cao, Q., Polone, E., Liu, W., Ammiraju, J. S., Kudrna, D., Wing, R., Untergasser, A., Bisseling, T., and Geurts, R. 2011 LysM-type mycorrhizal receptor recruited for rhizobium symbiosis in nonlegume Parasponia. Science 331:909-912.

Osborn, A. M., Moore, E. R., and Timmis, K. N. 2000. An evaluation of terminal-restriction fragment length polymorphism (T-RFLP) analysis for the study of microbial community structure and dynamics. Environ. Microbiol. 2:39-50.

Pajuelo, E., and Stougaard, J. 2005. Lotus japonicus as a model system. Pages 3-24 in: The Lotus japonicus Handbook. A. J. Marquez, ed. Springer, Dordrecht, The Netherlands.

Perret, X., Staehelin, C., and Broughton, W. J. 2000. Molecular basis of symbiotic promiscuity. Microbiol. Mol. Biol. Rev. 64:180-201.

Price, N. P., Relic, B., Talmont, F., Lewin, A., Prome, D., Pueppke, S. G. Maillet, F., Denarie, J., Prome, J. C., and Broughton, W. J. 1992. Broadhost-range Rhizobium species strain NGR234 secretes a family of carbamoylated, and fucosylated, nodulation signals that are O-acetylated or sulphated. Mol. Microbiol. 6:3575-3584.

Provorov, N. A., and Vorobyov, N. I. 2008. Equilibrium between the "genuine mutualists" and "symbiotic cheaters" in the bacterial population co-evolving with plants in a facultative symbiosis. Theor. Popul. Biol. 74:345-355.

Pueppke, S. G., and Broughton, W. J. 1999. Rhizobium sp. strain NGR234 and $R$. fredii USDA257 share exceptionally broad, nested host ranges. Mol. Plant-Microbe Interact. 12:293-318.

Puppo, A., Groten, K., Bastian, F., Carzaniga, R., Soussi, M., Lucas, M. M., de Felipe, M. R., Harrison, J., Vanacker, H., and Foyer, C. H. 2005 Legume nodule senescence: Roles for redox and hormone signalling in the orchestration of the natural aging process. New Phytol. 165:683701.

Radutoiu, S., Madsen, L. H., Madsen, E. B., Felle, H. H., Umehara, Y, Gronlund, M., Sato, S., Nakamura, Y., Tabata, S., Sandal, N., and Stougaard, J. 2003. Plant recognition of symbiotic bacteria requires two LysM receptor-like kinases. Nature 425:585-592.

Radutoiu, S., Madsen, L. H., Madsen, E. B., Jurkiewicz, A., Fukai, E. Quistgaard, E. M., Albrektsen, A. S., James, E. K., Thirup, S., and Stougaard, J. 2007. LysM domains mediate lipochitin-oligosaccharide recognition and $\mathrm{Nfr}$ genes extend the symbiotic host range. EMBO (Eur. Mol. Biol. Organ.) J. 26:3923-3935.

Rutherford, K., Parkhill, J., Crook, J., Horsnell, T., Rice, P., Rajandream, M. A., and Barrell, B. 2000. Artemis: Sequence visualization and annotation. Bioinformatics 16:944-945.

Schmeisser, C., Liesegang, H., Krysciak, D., Bakkou, N., Le Quere, A., Wollherr, A., Heinemeyer, I., Morgenstern, B., Pommerening-Roser, A., Flores, M., Palacios, R., Brenner, S., Gottschalk, G., Schmitz, R. A. Broughton, W. J., Perret, X., Strittmatter, A. W., and Streit, W. R. 2009. Rhizobium sp. strain NGR234 possesses a remarkable number of secretion systems. Appl. Environ. Microbiol. 75:4035-4045.

Schumpp, O., Crevecoeur, M., Broughton, W. J., and Deakin, W. J. 2009. Delayed maturation of nodules reduces symbiotic effectiveness of the Lotus japonicus-Rhizobium sp. NGR234 interaction. J. Exp. Bot. 60:581-590.

Schwedock, J., and Long, S. R. 1990. ATP sulphurylase activity of the nodP and nodQ gene products of Rhizobium meliloti. Nature 348:644647.

Schwedock, J. S., Liu, C., Leyh, T. S., and Long, S. R. 1994. Rhizobium meliloti NodP and NodQ form a multifunctional sulfate-activating complex requiring GTP for activity. J. Bacteriol. 176:7055-7064.

Smit, P., Limpens, E., Geurts, R., Fedorova, E., Dolgikh, E., Gough, C., and Bisseling, T. 2007. Medicago LYK3, an entry receptor in rhizobial nodulation factor signaling. Plant Physiol. 145:183-191.

Sprent, J. I. 1994. Evolution and diversity in the legume-rhizobium symbiosis: Chaos theory? Plant Soil 161:1-10.

Sprent, J. I. 2007. Evolving ideas of legume evolution and diversity: A taxonomic perspective on the occurrence of nodulation. New Phytol. $174: 11-25$

Squartini, A., Struffi, P., Doring, H., Selenska-Pobell, S., Tola, E., Giacomini, A., Vendramin, E., Velazquez, E., Mateos, P. F., Martinez- 
Molina, E., Dazzo, F. B., Casella, S., and Nuti, M. P. 2002. Rhizobium sullae sp. nov. (formerly 'Rhizobium hedysari'), the root-nodule microsymbiont of Hedysarum coronarium L. Int. J. Syst. Evol. Microbiol. 52:1267-1276.

Sytsma, K. J., Morawetz, J., Pires, J. C., Nepokroeff, M., Conti, E., Zjhra, M., Hall, J. C., and Chase, M. W. 2002. Urticalean rosids: Circumscription, rosid ancestry, and phylogenetics based on rbcL, trnL-F, and ndhF sequences. Am. J. Bot. 89:1531-1546.

Tamura, K., Peterson, D., Peterson, N., Stecher, G., Nei, M., and Kumar, S. 2011. MEGA5: Molecular evolutionary genetics analysis using maximum likelihood, evolutionary distance, and maximum parsimony methods. Mol. Biol. Evol. 28:2731-2739.

Terpolilli, J. J., O'Hara, G. W., Tiwari, R. P., Dilworth, M. J., and Howieson, J. G. 2008, The model legume Medicago truncatula A17 is poorly matched for $\mathrm{N}_{2}$ fixation with the sequenced microsymbiont Sinorhizobium meliloti 1021. New Phytol. 179:62-66.

Torres Tejerizo, G., Del Papa, M. F., Soria-Diaz, M. E., Draghi, W. Lozano, M., Giusti Mde, L., Manyani, H., Megias, M., Gil Serrano, A., Puhler, A., Niehaus, K., Lagares, A., and Pistorio, M. 2011. The nodulation of alfalfa by the acid-tolerant Rhizobium sp. strain LPU83 does not require sulfated forms of lipochitooligosaccharide nodulation signals. J. Bacteriol. 193:30-39.

Trinick, M. J. 1973. Symbiosis between Rhizobium and the non-legume, Trema aspera. Nature 244:459-460.

Trinick, M. J. 1979. Structure of nitrogen-fixing nodules formed by Rhizobium on roots of Parasponia andersonii Planch. Can. J. Microbiol. 25:565-578.

Trinick, M. J. 1980a. Growth of Parasponia in agar tube culture and symbiotic effectiveness of isolates from Parasponia spp. New Phytol. 85:37-45.

Trinick, M. J. 1980b. Relationships amongst the fast-growing rhizobia of Lablab purpureus, Leucaena leucocephala, Mimosa spp., Acacia farnesiana and Sesbania grandiflora and their affinities with other rhizobial groups. J. Appl. Bacteriol. 49:39-53.

Trinick, M. J., and Galbraith, J. 1976. Structure of root nodules formed by Rhizobium on the non-legume Trema cannabina var. scabra. Arch. Microbiol. 108:159-166.

Trinick, M. J., and Galbraith, J. 1980. The Rhizobium requirements of the non-legume Parasponia in relationship to the cross-inoculation group concept of legumes. New Phytol. 86:17-26.

Trinick, M. J., and Hadobas, P. A. 1988. Biology of the Parasponia-Bradyrhizobium symbiosis. Plant Soil 110:177-185.

Trinick, M. J., Goodchild, D. J., and Miller, C. 1989. Localization of bacteria and hemoglobin in root nodules of Parasponia andersonii containing both Bradyrhizobium strains and Rhizobium leguminosarum biovar trifolii. Appl. Environ. Microbiol. 55:2046-2055.

Van de Velde, W., Guerra, J. C., De Keyser, A., De Rycke, R., Rombauts, S., Maunoury, N., Mergaert, P., Kondorosi, E., Holsters, M., and Goormachtig, S. 2006. Aging in legume symbiosis. A molecular view on nodule senescence in Medicago truncatula. Plant Physiol. 141:711720.

Van Domselaar, G. H., Stothard, P., Shrivastava, S., Cruz, J. A., Guo, A., Dong, X., Lu, P., Szafron, D., Greiner, R., and Wishart, D. S. 2005 BASys: A web server for automated bacterial genome annotation. Nucleic Acids Res. 33:W455-W459.

Waelkens, F., Voets, T., Vlassak, K., Vanderleyden, J., and Van Rhijn, P. 1995. The nodS gene of Rhizobium tropici strain CIAT899 is necessary for nodulation on Phaseolus vulgaris and on Leucaena leucocephala. Mol. Plant-Microbe Interact. 8:147-154.

Wang, D., Griffitts, J., Starker, C., Fedorova, E., Limpens, E., Ivanov, S., Bisseling, T., and Long, S. 2010. A nodule-specific protein secretory pathway required for nitrogen-fixing symbiosis. Science 327:11261129.

Webster, G., Poulton, P. R., Cocking, E. C., and Davey, M. R. 1995. The nodulation of micro-propagated plants of Parasponia andersonii by tropical legume rhizobia. J. Exp. Bot. 46:1131-1137.

Witzany, G. 2011. Rhizobia, legumes and nitrogen fixation. Pages 309-311 in: Biocommunication in soil microorganisms, Ed. 1, Vol. 1. G. Witzany, ed. Springer, Heidelberg, Germany.

Wong, C. H., and Patchamuthu, R. 1988. Rhizobia in tropical legumes: Ineffective nodulation of Arachis hypogaea $\mathrm{L}$. by fast-growing strains. Soil Biol. Biochem. 20:677-681.

Yasuta, T., Okazaki, S., Mitsui, H., Yuhashi, K. I., Ezura, H., an Minamisawa, K. 2001. DNA sequence and mutational analysis of Rhizobitoxine biosynthesis genes in Bradyrhizobium elkanii. Appl. Environ. Microbiol. 67:4999-5009. 